\title{
Application of likelihood ratio and posterior probability density in sex estimation from level two fingerprint features among Hausa ethnic group
}

Lawan Hassan Adamu ${ }^{1 *}$ and Magaji Garba Taura ${ }^{1,2}$

\begin{abstract}
Background: In forensic sciences, the nature and variability of configurations of epidermal ridge minutiae has practically been explored in the evaluation and comparison of fingerprints, including partial fingerprints. The objectives of the present study were to determine the potential of fingerprint minutiae (level two features) in estimation of sex using likelihood ratio and posterior probability density among Hausa population. Secondly, to determine which of the minutiae have more of the estimation power compared to others.

Methods: A total of 420 thumbprints from 210 participants were analyzed. The minutiae density was determined within a circle whose diameter cuts 18 ridges and passing through the nucleus of the fingerprints. Posterior probability density and likelihood ratio were used to estimate the sex.

Results: The results showed that the median of minutiae count in males tends to be significantly higher in right ridge ending and ridge enclosure. Similarly, in the left thumb, the significantly higher minutiae count in males was observed in the ridge ending and ridge dot. In all the minutiae types, higher minutiae density favors males compared to the females. Likewise, in all the minutiae density, except for right ridge convergent and bifurcation and ridge ending, absence of any of the minutiae in the thumb favored female participants.

Conclusion: Increase in minutiae density was likely to infer males more than females. Ridge ending minutiae was observed to have higher discriminating power shown by higher likelihood ratio for sex inference among Hausa population.
\end{abstract}

Keywords: Forensic science, Minutiae density, Likelihood ratio, Sex inference, Hausa ethnic group

\section{Background}

The tips of human digits are characterized with genetically and environmentally determined series of ridges and furrows, generally referred to as fingerprints (Cummins and Midlo 1943; Holt 1952; Holt 1968; Schaumann and Alter 1976; Reed et al. 2006). Development of epidermal ridges is first seen in the $10^{\text {th }}-11^{\text {th }}$ weeks of gestation and is marked by cell proliferations in the basal layer of the epidermis (Mulvihill and Smith 1969; Babler 1978). These proliferations form the primary ridges, which

\footnotetext{
* Correspondence: alhassan.ana@buk.edu.ng

'Department of Anatomy, Faculty of Basic Medical Sciences, College of Health Sciences, Bayero University Kano, Kano, Nigeria

Full list of author information is available at the end of the article
}

extend into the dermis and increase in number as new ridges, a secondary ridge, forms between them and on the periphery of the pattern (Hale 1952). The configurations of the fingerprint enlarge as the hands and feet grow, but the characteristics of the print remain unchanged once the dermal ridges become fully differentiated at about the 17th week of fetal development (Hale 1952; Babler 1978; Borecki et al. 1985). This permanence of fingerprints is one of the characteristics that make them useful to disciplines like anthropology and forensic science. The process of ridge development is integral to the understanding of fingerprints and their purpose in forensic and anthropological investigations (Fournier and Ross 2016). 
Fingerprint friction ridge details are described in a hierarchical order ranging from level one to level three (Hong et al. 1998; Fournier and Ross 2016). Level one is for revealing macro detail such as ridge flow, which allows pattern classification and ridge counting (Jain et al. 2007; Ashbaugh 1992; Langenburg 2004). This detail is not specific enough to be applied for personal identification. It is mainly used by biological anthropologist to differentiate between population (Arrieta et al. 2003; Scheil et al. 2005; Dorjee et al. 2015) and for the determination of heritability, ethnicity, and sex (Reed et al. 2006; Adamu et al. 2016). Level 2 features called minutiae refer to the shape, direction, and orientation of the trait that forms the friction ridges, and is used mainly for the purpose of establishing identity (Langenburg 2004; Nickell and Fischer 1999; Bennett and Perumal 2011). This is because minutiae are unique in their quantity and orientation in each individual fingerprint (Cummins 1967). The level 3 features, which are also used for purpose of identity, deal with individual ridge structure such as ridge path deviation, ridge edge and shape, local ridge quality, distance between pores, size and shape of pores (Langenburg 2004; Working draft of CDEFFS 2008).

Incorporation of biological factors into the process of latent fingerprint identifications and use of statistical approach to minimize the error rate should not be overlooked as emphasized by National Academy of Science (NAS) Report of 2009 (National Academy of Sciences 2009; Fournier and Ross 2016). However, it was also claimed that minutiae counts are largely a random event (Cummins and Midlo 1943). The application of fingerprints in sex discrimination receives less attention among Hausas population. Only of recent logistic regression analysis was used to predict sex among Hausa population (Adamu et al. 2017). However, there is paucity of literature on the use of likelihood ratio and posterior probability in sex inference from minutiae density. The objectives of the present study were to determine the potential of fingerprint minutiae (level two features) in estimation of sex using likelihood ratio and posterior probability density among Hausa population as well as to determine which of the minutiae has more of the estimation power compared to others.

\section{Methods}

\section{Subjects}

The participants of the study were from Hausa ethnic group of Kano state. The state is one of the most populous states in Nigeria. The urban area of the state comprises six major local government areas (LGAs) and covers about $137 \mathrm{~km}^{2}$. The principal inhabitants of the state belong to Hausa ethnic group (Barau 2007). The study population comprises of 210 participants within the age range of $18-25$ years with 1:1 males to females ratio. A total of 420 thumbprints areas were analyzed in the study. Any participants with hand deformity, unclear impression and non Hausa ethnic group of Kano State, Nigeria were excluded from the study. Informed consent was obtained from all participants before their enrolment in the study. Ethical approval was obtained from the ethical committee of Kano state Hospitals Management Board and Ahmadu Bello University, Zaria Faculty of Medicine and Teaching Hospital, (ABUTHZ/HREC/ 506/2015).

\section{Thumbprint capturing}

Live scanner (digital persona, China) was used to capture thumbprint of each participant. Software (Printanalyse) was designed using Microsoft visual basic (version 6.0) programming language for capturing and determination of minutiae density. Each captured plain thumbprint was saved with the name of digit (thumb), sex of the participants (male or female), side of the digit (left or right) and unique code of the participants. The thumbprints were classified into three basic patterns; loops, whorl and arches. Two versions, original and enlarged (at a ratio of 7.74), were captured. The original size was used for scaling purpose and enlarged version was used to determine the minutiae density. For the purpose of ensuring real size measurements, Cummins and Midlo (1943) ink method was adopted to capture the plain thumbprints of 30 randomly selected participants.

\section{Minutiae counts and classification}

The minutiae density was determined within a circle whose diameter cuts 18 ridges, and passing through the nucleus of the fingerprints as described in the previous methods (Okajima 1970; Adamu et al. 2017). Nine types of minutiae bifurcation, convergent, ridge ending, ridge enclosure (small), ridge enclosure (big), ridge fragment (small), ridge fragment (big), ridge dot between the ridges and dot within the ridges as defined by previous workers (Gutierrez-Redomero et al. 2007; Adamu et al. 2017) were narrowed to five types, ridge bifurcation (bifurcation\& convergence), ridge ending, ridge enclosure (small \& big), short ridge (small and big fragments), ridge dot (dot between or within the ridges).The selection of five minutiae types in this study was based on their distinctive characteristics and they are frequently encountered in comparison of fingerprints by forensic expert (Fournier and Ross 2016).

\section{Calculation of likelihood ratio and favor odd}

The calculated likelihood (LR) gives the strength of support for one of the hypotheses: $\mathrm{C}$ or $\mathrm{C}^{\prime}$. Posterior probabilities $\mathrm{P}(\mathrm{C} / \mathrm{MD})$ and $\mathrm{P}\left(\mathrm{C}^{\prime} / \mathrm{MD}\right)$ were calculated using Bayes' theorem (Grieve and Dunlop 1992). Favored odds for support of the most likely hypothesis for a given 
minutia density $\mathrm{P}(\mathrm{MD} / \mathrm{C})$ and $\mathrm{P}\left(\mathrm{MD} / \mathrm{C}^{\prime}\right)$ were obtained from information of both LR computations and posterior probabilities. The likelihood ratio (LR) was calculated using relative frequency of minutia density (MD).

$$
\begin{aligned}
\mathrm{LR} & =\frac{\text { probability of observing a given minutia density, if the donor was male }(C)}{\text { probability of observing a given minutia density, }} \\
& \text { if the donor was female }\left(C^{\prime}\right)
\end{aligned}
$$

Where MD $\frac{\text { Frequency of a given minutia density }}{\text { Total frequency of all minutia density }}, \mathrm{C}$ is the male donor, and $C^{\prime}$ is the female donor, and assuming the equal probability between the sexes $\mathrm{P}(\mathrm{C})=\mathrm{P}\left(\mathrm{C}^{\prime}\right)=0.5$.

The ridge density with likelihood ratio of $>1$ is more likely to be of male origin, for $<1$ is likely to female origin. The favor odd (FO) was calculated as; $\mathrm{FO}=\frac{\mathrm{P}(\mathrm{MD} / \mathrm{C})}{\mathrm{P}(\mathrm{MD} / \mathrm{C})+\mathrm{P}\left(\mathrm{MD} / \mathrm{C}^{\prime}\right)}$.

Frequencies for different types of patterns and mean ridge density were also determined.

\section{Statistical analyses and Repeatability of Measurements}

The data was subjected to Kolmogorov-Smirnov test of normality. The minutiae count was not normally distributed $(P<0.001)$. The data was expressed in frequency and percentiles (using box and whiskers plot). Mann Whitney test was employed for comparing the median minutiae count between males and females. The consistency and repeatability of minutiae count was assessed using paired sample t- test. Two sets of measurements taken from 30 randomly selected participants were used for this purpose. The interval between the first and second measurements was at least 1 week. There was no significant difference $(P>0.05)$ between the first and second minutiae counts. All the analyses were carried out using SPSS version 20 (IBM Corporation, NY, USA). $P<0.05$ was considered as level of significance.

\section{Results}

Figure 1 showed the frequency distribution of the fingerprint pattern according to sex and side of the thumb. In both sexes, the loops were the most frequent in right thumb (males had 57 and females 64) and left thumb (males had 69 and females had 58) followed by the whorls (right thumb, male had 41, females had 36 and left thumb, male had 28, females had 39) and the least was the arches (right thumb, male had 7, females had five and left thumb, both sexes had eight). In males, there were more whorls in right thumb compared to left. Reverse frequency of whorls were observed in females. The frequency of arches was the same in left thumb in both sexes, but higher in right thumb in male.

Figure 2 shows the box and whisker plot of minutiae counts of males and females among Hausa population of Nigeria. The ridge ending and bifurcation combined with convergence exhibited higher median values compared to the other minutiae types. A significant
Right thumbprint of male participants

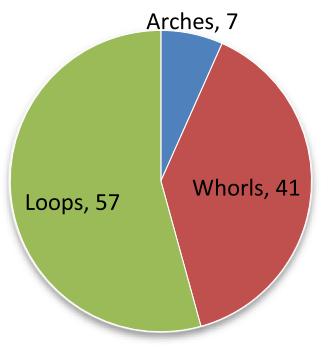

Right thumbprint of female participants

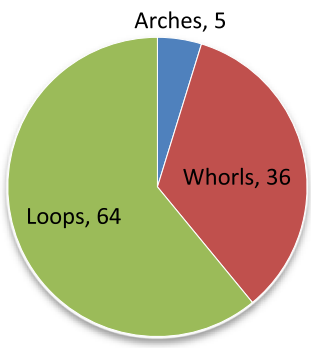

Left thumbprint of male participants

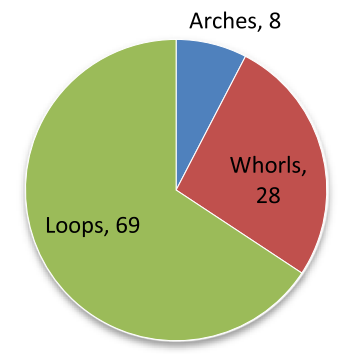

Left thumbprint of female participants

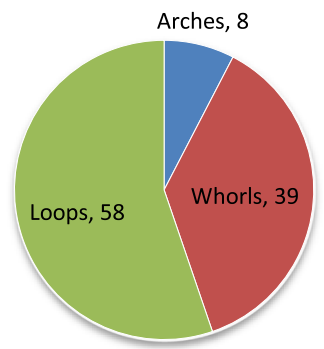

Fig. 1 Frequency distribution of fingerprint patterns in left and right thumbs of males and females Hausa population of Kano state, Nigeria 

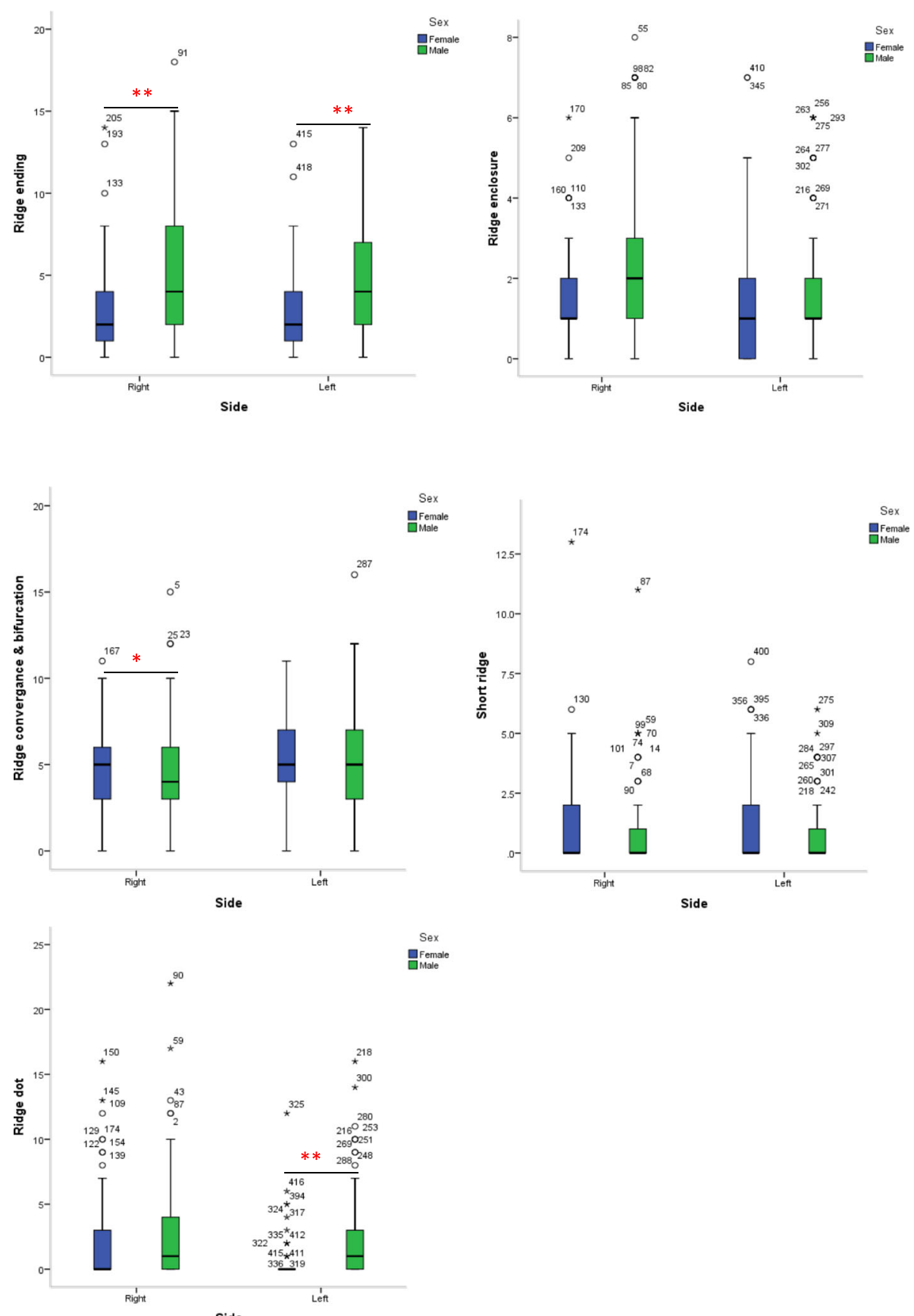

Sex

Fig. 2 Sex differences in five different types of minutiae (ridge ending, enclosure, convergence \& bifurcation, short and dot) of study population. The data were analyzed using Mann Whitney test. Mid-point (black) of the box represents the median; the bottom of the box indicates 25 th percentile (2nd quartile) and top of the box 75th percentile (3rd quartile). The lower and upper limit of the whiskers (T-bars at the bottom and top of the box) represents the minimum to maximum. The dot/asterisk (black) indicates outliers [values that do not fall in the whiskers (1.5 times the height of the box)] and the numbers indicate the serial number of the outliers in the data series ${ }^{* *} P<0.01,{ }^{*} P<0.05$

difference was observed in ridge ending and ridge bifurcation and convergence in the right thumbprint. In the left thumbprint, the significant difference was observed in ridge ending and ridge dot. Males exhibited higher median value in minutiae counts compared to females.
Tables 1, 2, 3, 4 and 5 show frequency, likelihood ratio and favor odd of different ridge minutiae density of right and left thumbprints within a circle that cuts across about 18 ridges with diameter of the circle passing through the nucleus (center of the thumbprints). Table 1 
Table 1 Frequency, likelihood ratio and favor odd of different ridge bifurcation and convergent density of right and left thumbprints

\begin{tabular}{|c|c|c|c|c|c|c|c|c|c|c|}
\hline \multirow[t]{3}{*}{ Side } & \multirow[t]{3}{*}{ MD } & \multicolumn{7}{|c|}{ Ridge bifurcation and convergence } & & \\
\hline & & \multirow{2}{*}{$\begin{array}{l}\text { Male } \\
\text { Frq }\end{array}$} & \multirow{2}{*}{$\begin{array}{l}\text { Female } \\
\text { Frq }\end{array}$} & \multirow{2}{*}{$\begin{array}{l}\text { Male } \\
\text { rMnt }\end{array}$} & \multirow{2}{*}{$\begin{array}{l}\text { Female } \\
\text { rMnt }\end{array}$} & \multirow{2}{*}{$\begin{array}{l}\text { Male } \\
\text { P (rMnt/C) }\end{array}$} & \multirow{2}{*}{$\begin{array}{l}\text { Female } \\
\text { P (rMnt/C') }\end{array}$} & \multirow{2}{*}{$\begin{array}{l}\text { Likelihood } \\
\text { Male }\end{array}$} & \multicolumn{2}{|c|}{ Favor odd } \\
\hline & & & & & & & & & Male & Female \\
\hline \multirow[t]{13}{*}{ Right } & 0 & 40 & 36 & 0.38 & 0.34 & 0.76 & 0.69 & 1.11 & 0.53 & 0.47 \\
\hline & 1 & 47 & 36 & 0.45 & 0.34 & 0.90 & 0.69 & 1.31 & 0.57 & 0.43 \\
\hline & 2 & 46 & 49 & 0.44 & 0.47 & 0.88 & 0.93 & 0.94 & 0.48 & 0.52 \\
\hline & 3 & 38 & 36 & 0.36 & 0.34 & 0.72 & 0.69 & 1.06 & 0.51 & 0.49 \\
\hline & 4 & 19 & 23 & 0.18 & 0.22 & 0.36 & 0.44 & 0.83 & 0.45 & 0.55 \\
\hline & 5 & 11 & 10 & 0.10 & 0.10 & 0.21 & 0.19 & 1.10 & 0.52 & 0.48 \\
\hline & 6 & 6 & 13 & 0.06 & 0.12 & 0.11 & 0.25 & 0.46 & 0.32 & 0.68 \\
\hline & 7 & 1 & 3 & 0.01 & 0.03 & 0.02 & 0.06 & 0.33 & 0.25 & 0.75 \\
\hline & 8 & - & 2 & 0.00 & 0.02 & 0.00 & 0.04 & 0.00 & 0.00 & 1.00 \\
\hline & 9 & - & 1 & 0.00 & 0.01 & 0.00 & 0.02 & 0.00 & 0.00 & 1.00 \\
\hline & 10 & - & 1 & 0.00 & 0.01 & 0.00 & 0.02 & 0.00 & 0.00 & 1.00 \\
\hline & 11 & 1 & - & 0.01 & 0.00 & 0.02 & 0.00 & - & 1.00 & 0.00 \\
\hline & 15 & 1 & - & 0.01 & 0.00 & 0.02 & 0.00 & - & 1.00 & 0.00 \\
\hline \multirow[t]{13}{*}{ Left } & 0 & 45 & 51 & 0.43 & 0.49 & 0.86 & 0.97 & 0.88 & 0.47 & 0.53 \\
\hline & 1 & 41 & 37 & 0.39 & 0.35 & 0.78 & 0.70 & 1.11 & 0.53 & 0.47 \\
\hline & 2 & 40 & 28 & 0.38 & 0.27 & 0.76 & 0.53 & 1.43 & 0.59 & 0.41 \\
\hline & 3 & 26 & 21 & 0.25 & 0.20 & 0.50 & 0.40 & 1.24 & 0.55 & 0.45 \\
\hline & 4 & 17 & 28 & 0.16 & 0.27 & 0.32 & 0.53 & 0.61 & 0.38 & 0.62 \\
\hline & 5 & 15 & 18 & 0.14 & 0.17 & 0.29 & 0.34 & 0.83 & 0.45 & 0.55 \\
\hline & 6 & 5 & 17 & 0.05 & 0.16 & 0.10 & 0.32 & 0.29 & 0.23 & 0.77 \\
\hline & 7 & 8 & 4 & 0.08 & 0.04 & 0.15 & 0.08 & 2.00 & 0.67 & 0.33 \\
\hline & 8 & 4 & 4 & 0.04 & 0.04 & 0.08 & 0.08 & 1.00 & 0.50 & 0.50 \\
\hline & 9 & 5 & 1 & 0.05 & 0.01 & 0.10 & 0.02 & 5.00 & 0.83 & 0.17 \\
\hline & 10 & 1 & - & 0.01 & 0.00 & 0.02 & 0.00 & - & 1.00 & 0.00 \\
\hline & 11 & 2 & 1 & 0.02 & 0.01 & 0.04 & 0.02 & 2.00 & 0.67 & 0.33 \\
\hline & 16 & 1 & - & 0.01 & 0.00 & 0.02 & 0.00 & - & 1.00 & 0.00 \\
\hline
\end{tabular}

$M D$ minutiae density, Frq frequency, $r M n t$ relative minutiae, $C ; C^{\prime} ; 0.5$

Bold text indicates manutiae density with likelihood ratio that favor males or gives equal chance for both sexes

shows frequency, likelihood ratio and favor odd of different ridges bifurcation and convergent density of right and left thumbprints. It was observed that sex inference from the minutiae density was random, however, the odd of being male tend to be at two extremes, lower and higher minutiae density. In the right thumbprints, the ridge bifurcation and convergent density of $0,1,3,5,11$ and 15 tend to infer male sex (likelihood $>1$ ). For the left $1,2,3,7$, and $\geq 9$ was more likely to infer males. Table 2 shows the frequency, likelihood ratio and favor odd of different ridge ending density of right and left thumbprints. A more definite pattern of sex inference was observed in ridge ending density. It was noted that $\geq 4$ was more likely to be of male origin with exception of 6 and 14 ridge ending density, which was observed to be more of female origin. Similarly, ridge ending density of $\geq 4$ in the left thumbprints was more likely to be of male origin with exception of eight ridge ending, which showed an equal probability. Combining the two sides, it was observed that $<4$ ridge ending density was likely to be of female origin.

The frequency, likelihood ratio and favor odd of different ridge enclosure of right and left thumbprints were shown in Table 3. It was observed that ridge enclosure density of $\leq 2$ was more likely to be of male origin except for 3. However, both sexes had equal favor odd for absence of these minutiae. For the left thumbprints, ridge enclosure of 3 and 7 were more likely to be of female origin, moreover, absence of the ridge enclosure predicted more of female origin. Table 4 showed frequency, likelihood ratio and favor odd of short ridge density of right and left thumbprints. Only short ridge density of 1 and 11 were more likely of male origin. For the left thumbprints 1 and 4 were more likely of male 
Table 2 Frequency, likelihood ratio and favor odd of different ridge ending density of right and left thumbprints

\begin{tabular}{|c|c|c|c|c|c|c|c|c|c|c|}
\hline \multirow[t]{3}{*}{ Side } & \multirow[t]{3}{*}{ MD } & \multicolumn{7}{|c|}{ Ridge ending } & & \\
\hline & & Male & Female & Male & Female & Male & Female & $\overline{\text { Likelihood }}$ & \multicolumn{2}{|l|}{ Favor odd } \\
\hline & & Frq & Frq & $\mathrm{MD}$ & $\mathrm{MD}$ & $\mathrm{P}(\mathrm{MD} / \mathrm{C})$ & $\mathrm{P}\left(\mathrm{MD} / \mathrm{C}^{\prime}\right)$ & & Male & Female \\
\hline \multirow[t]{17}{*}{ Right } & 0 & 8 & 9 & 0.08 & 0.09 & 0.15 & 0.17 & 0.89 & 0.47 & 0.53 \\
\hline & 1 & 7 & 20 & 0.07 & 0.19 & 0.13 & 0.38 & 0.35 & 0.26 & 0.74 \\
\hline & 2 & 13 & 25 & 0.12 & 0.24 & 0.25 & 0.48 & 0.52 & 0.34 & 0.66 \\
\hline & 3 & 12 & 13 & 0.11 & 0.12 & 0.23 & 0.25 & 0.92 & 0.48 & 0.52 \\
\hline & 4 & 13 & 12 & 0.12 & 0.11 & 0.25 & 0.23 & 1.08 & 0.52 & 0.48 \\
\hline & 5 & 10 & 9 & 0.10 & 0.09 & 0.19 & 0.17 & 1.11 & 0.53 & 0.47 \\
\hline & 6 & 6 & 9 & 0.06 & 0.09 & 0.11 & 0.17 & 0.67 & 0.40 & 0.60 \\
\hline & 7 & 9 & 3 & 0.09 & 0.03 & 0.17 & 0.06 & 3.00 & 0.75 & 0.25 \\
\hline & 8 & 9 & 2 & 0.09 & 0.02 & 0.17 & 0.04 & 4.50 & 0.82 & 0.18 \\
\hline & 9 & 6 & - & 0.06 & 0.00 & 0.11 & 0.00 & - & 1.00 & 0.00 \\
\hline & 10 & 3 & 1 & 0.03 & 0.01 & 0.06 & 0.02 & 3.00 & 0.75 & 0.25 \\
\hline & 11 & 3 & - & 0.03 & 0.00 & 0.06 & 0.00 & - & 1.00 & 0.00 \\
\hline & 12 & 1 & - & 0.01 & 0.00 & 0.02 & 0.00 & - & 1.00 & 0.00 \\
\hline & 13 & 3 & 1 & 0.03 & 0.01 & 0.06 & 0.02 & 3.00 & 0.75 & 0.25 \\
\hline & 14 & - & 1 & 0.00 & 0.01 & 0.00 & 0.02 & 0.00 & 0.00 & 1.00 \\
\hline & 15 & 1 & - & 0.01 & 0.00 & 0.02 & 0.00 & - & 1.00 & 0.00 \\
\hline & 18 & 1 & - & 0.01 & 0.00 & 0.02 & 0.00 & - & 1.00 & 0.00 \\
\hline \multirow[t]{15}{*}{ Left } & 0 & 8 & 14 & 0.08 & 0.13 & 0.15 & 0.27 & 0.57 & 0.36 & 0.64 \\
\hline & 1 & 8 & 19 & 0.08 & 0.18 & 0.15 & 0.36 & 0.42 & 0.30 & 0.70 \\
\hline & 2 & 12 & 24 & 0.11 & 0.23 & 0.23 & 0.46 & 0.50 & 0.33 & 0.67 \\
\hline & 3 & 10 & 15 & 0.10 & 0.14 & 0.19 & 0.29 & 0.67 & 0.40 & 0.60 \\
\hline & 4 & 18 & 17 & 0.17 & 0.16 & 0.34 & 0.32 & 1.06 & 0.51 & 0.49 \\
\hline & 5 & 16 & 10 & 0.15 & 0.10 & 0.30 & 0.19 & 1.60 & 0.62 & 0.38 \\
\hline & 6 & 5 & 1 & 0.05 & 0.01 & 0.10 & 0.02 & 5.00 & 0.83 & 0.17 \\
\hline & 7 & 7 & 2 & 0.07 & 0.02 & 0.13 & 0.04 & 3.50 & 0.78 & 0.22 \\
\hline & 8 & 1 & 1 & 0.01 & 0.01 & 0.02 & 0.02 & 1.00 & 0.50 & 0.50 \\
\hline & 9 & 7 & - & 0.07 & 0.00 & 0.13 & 0.00 & - & 1.00 & 0.00 \\
\hline & 10 & 2 & - & 0.02 & 0.00 & 0.04 & 0.00 & - & 1.00 & 0.00 \\
\hline & 11 & 3 & 1 & 0.03 & 0.01 & 0.06 & 0.02 & 3.00 & 0.75 & 0.25 \\
\hline & 12 & 3 & - & 0.03 & 0.00 & 0.06 & 0.00 & - & 1.00 & 0.00 \\
\hline & 13 & 3 & 1 & 0.03 & 0.01 & 0.06 & 0.02 & 3.00 & 0.75 & 0.25 \\
\hline & 14 & 2 & - & 0.02 & 0.00 & 0.04 & 0.00 & - & 1.00 & 0.00 \\
\hline
\end{tabular}

MD minutiae density, Frq frequency, rMnt relative minutiae, $C_{;} C^{\prime} ; 0.5$

Bold text indicates manutiae density with likelihood ratio that favor males or gives equal chance for both sexes

origin. In both sides, absences of short ridge indicate more of female origin. Table 5 showed frequency, likelihood ratio and favor odd of different ridge dot of right and left thumbprints. It was observed that $0,3,6,7,10$, 16 and 0,12 ridge dot density were more likely to be of female origin in right and left thumbprints respectively.

\section{Discussion}

Biological uniqueness and constancy of fingerprints have been considered overtime as important characteristic to be utilized within the domains of forensic community (Scientific Working Group on Friction Ridge Analysis, Study, and Technology 2002).This makes the fingerprints an ideal biological feature for personal identification in criminal events, victims of mass disasters among others. Three levels system of analysis was usually employed for fingerprint comparison. This indicates stronger and specific levels of individualization for better comparison (SWGFRA, Scientific Working Group on Friction Ridge Analysis, Study, and Technology 2002; 
Table 3 Frequency, likelihood ratio and favor odd of different ridge enclosure density of right and left thumbprints

\begin{tabular}{|c|c|c|c|c|c|c|c|c|c|c|}
\hline \multirow[t]{3}{*}{ Side } & \multirow[t]{3}{*}{ MD } & \multicolumn{7}{|c|}{ Ridge enclosure } & & \\
\hline & & \multirow{2}{*}{$\begin{array}{l}\text { Male } \\
\text { Frq }\end{array}$} & \multirow{2}{*}{$\begin{array}{l}\text { Female } \\
\text { Frq }\end{array}$} & \multirow{2}{*}{$\begin{array}{l}\text { Male } \\
\text { MD }\end{array}$} & \multirow{2}{*}{$\begin{array}{l}\text { Female } \\
\text { MD }\end{array}$} & \multirow{2}{*}{$\begin{array}{l}\text { Male } \\
\mathrm{P}(\mathrm{MD} / \mathrm{C})\end{array}$} & \multirow{2}{*}{$\begin{array}{l}\text { Female } \\
\mathrm{P}\left(\mathrm{MD} / \mathrm{C}^{\prime}\right)\end{array}$} & \multirow[t]{2}{*}{ Likelihood } & \multicolumn{2}{|c|}{ Favor odd } \\
\hline & & & & & & & & & Male & Female \\
\hline \multirow[t]{9}{*}{ Right } & 0 & 26 & 26 & 0.25 & 0.25 & 0.50 & 0.50 & 1.00 & 0.50 & 0.50 \\
\hline & 1 & 22 & 35 & 0.21 & 0.33 & 0.42 & 0.67 & 0.63 & 0.39 & 0.61 \\
\hline & 2 & 23 & 19 & 0.22 & 0.18 & 0.44 & 0.36 & 1.21 & 0.55 & 0.45 \\
\hline & 3 & 12 & 19 & 0.11 & 0.18 & 0.23 & 0.36 & 0.63 & 0.39 & 0.61 \\
\hline & 4 & 8 & 4 & 0.08 & 0.04 & 0.15 & 0.08 & 2.00 & 0.67 & 0.33 \\
\hline & 5 & 3 & 1 & 0.03 & 0.01 & 0.06 & 0.02 & 3.00 & 0.75 & 0.25 \\
\hline & 6 & 3 & 1 & 0.03 & 0.01 & 0.06 & 0.02 & 3.00 & 0.75 & 0.25 \\
\hline & 7 & 7 & - & 0.07 & 0.00 & 0.13 & 0.00 & - & 1.00 & 0.00 \\
\hline & 8 & 1 & - & 0.01 & 0.00 & 0.02 & 0.00 & - & 1.00 & 0.00 \\
\hline \multirow[t]{8}{*}{ Left } & 0 & 23 & 35 & 0.22 & 0.33 & 0.44 & 0.67 & 0.66 & 0.40 & 0.60 \\
\hline & 1 & 33 & 30 & 0.31 & 0.29 & 0.63 & 0.57 & 1.10 & 0.52 & 0.48 \\
\hline & 2 & 24 & 21 & 0.23 & 0.20 & 0.46 & 0.40 & 1.14 & 0.53 & 0.47 \\
\hline & 3 & 9 & 12 & 0.09 & 0.11 & 0.17 & 0.23 & 0.75 & 0.43 & 0.57 \\
\hline & 4 & 5 & 3 & 0.05 & 0.03 & 0.10 & 0.06 & 1.67 & 0.63 & 0.38 \\
\hline & 5 & 6 & 2 & 0.06 & 0.02 & 0.11 & 0.04 & 3.00 & 0.75 & 0.25 \\
\hline & 6 & 5 & - & 0.05 & 0.00 & 0.10 & 0.00 & - & 1.00 & 0.00 \\
\hline & 7 & - & 2 & 0.00 & 0.02 & 0.00 & 0.04 & 0.00 & 0.00 & 1.00 \\
\hline
\end{tabular}

MD minutiae density, Frq frequency, rMnt relative minutiae, $C_{;} C^{\prime} ; 0.5$

Bold text indicates manutiae density with likelihood ratio that favor males or gives equal chance for both sexes

Table 4 Frequency, likelihood ratio and favor odd of different short ridge density of right and left thumbprints

\begin{tabular}{|c|c|c|c|c|c|c|c|c|c|c|}
\hline \multirow[t]{3}{*}{ Side } & \multirow[t]{3}{*}{$\mathrm{MD}$} & \multicolumn{7}{|c|}{ Short ridge } & & \\
\hline & & \multirow{2}{*}{$\begin{array}{l}\text { Male } \\
\text { Frq }\end{array}$} & \multirow{2}{*}{$\begin{array}{l}\text { Female } \\
\text { Frq }\end{array}$} & \multirow{2}{*}{$\begin{array}{l}\text { Male } \\
\text { MD }\end{array}$} & \multirow{2}{*}{$\begin{array}{l}\text { Female } \\
\text { MD }\end{array}$} & \multirow{2}{*}{$\begin{array}{l}\text { Male } \\
\mathrm{P}(\mathrm{MD} / \mathrm{C})\end{array}$} & \multirow{2}{*}{$\begin{array}{l}\text { Female } \\
\text { P (MD/C') }\end{array}$} & \multirow[t]{2}{*}{ Likelihood } & \multicolumn{2}{|c|}{ Favor odd } \\
\hline & & & & & & & & & Male & Female \\
\hline \multirow[t]{9}{*}{ Right } & 0 & 57 & 59 & 0.54 & 0.56 & 1.09 & 1.12 & 0.97 & 0.49 & 0.51 \\
\hline & 1 & 23 & 17 & 0.22 & 0.16 & 0.44 & 0.32 & 1.35 & 0.58 & 0.43 \\
\hline & 2 & 13 & 13 & 0.12 & 0.12 & 0.25 & 0.25 & 1.00 & 0.50 & 0.50 \\
\hline & 3 & 3 & 4 & 0.03 & 0.04 & 0.06 & 0.08 & 0.75 & 0.43 & 0.57 \\
\hline & 4 & 3 & 5 & 0.03 & 0.05 & 0.06 & 0.10 & 0.60 & 0.38 & 0.63 \\
\hline & 5 & 5 & 5 & 0.05 & 0.05 & 0.10 & 0.10 & 1.00 & 0.50 & 0.50 \\
\hline & 6 & - & 1 & 0.00 & 0.01 & 0.00 & 0.02 & 0.00 & 0.00 & 1.00 \\
\hline & 11 & 1 & - & 0.01 & 0.00 & 0.02 & 0.00 & - & 1.00 & 0.00 \\
\hline & 13 & - & 1 & 0.00 & 0.01 & 0.00 & 0.02 & - & 0.00 & 1.00 \\
\hline \multirow[t]{8}{*}{ Left } & 0 & 61 & 75 & 0.58 & 0.71 & 1.16 & 1.43 & 0.81 & 0.45 & 0.55 \\
\hline & 1 & 26 & 3 & 0.25 & 0.03 & 0.50 & 0.06 & 8.67 & 0.90 & 0.10 \\
\hline & 2 & 6 & 13 & 0.06 & 0.12 & 0.11 & 0.25 & 0.46 & 0.32 & 0.68 \\
\hline & 3 & 4 & 5 & 0.04 & 0.05 & 0.08 & 0.10 & 0.80 & 0.44 & 0.56 \\
\hline & 4 & 6 & 2 & 0.06 & 0.02 & 0.11 & 0.04 & 3.00 & 0.75 & 0.25 \\
\hline & 5 & 1 & 3 & 0.01 & 0.03 & 0.02 & 0.06 & 0.33 & 0.25 & 0.75 \\
\hline & 6 & 1 & 3 & 0.01 & 0.03 & 0.02 & 0.06 & 0.33 & 0.25 & 0.75 \\
\hline & 8 & - & 1 & 0.00 & 0.01 & 0.00 & 0.02 & 0.00 & 0.00 & 1.00 \\
\hline
\end{tabular}


Table 5 Frequency, likelihood ratio and favor odd of different ridge dot density of right and left thumbprints

\begin{tabular}{|c|c|c|c|c|c|c|c|c|c|c|}
\hline \multirow[t]{3}{*}{ Side } & \multirow[t]{3}{*}{ MD } & \multicolumn{7}{|c|}{ Ridge dot } & & \\
\hline & & \multirow{2}{*}{$\begin{array}{l}\text { Male } \\
\text { Frq }\end{array}$} & \multirow{2}{*}{$\begin{array}{l}\text { Female } \\
\text { Frq }\end{array}$} & \multirow{2}{*}{$\begin{array}{l}\text { Male } \\
\text { MD }\end{array}$} & \multirow{2}{*}{$\begin{array}{l}\text { Female } \\
\text { MD }\end{array}$} & \multirow{2}{*}{$\begin{array}{l}\text { Male } \\
\mathrm{P}(\mathrm{MD} / \mathrm{C})\end{array}$} & \multirow{2}{*}{$\begin{array}{l}\text { Female } \\
\text { P (MD/C') }\end{array}$} & \multirow{2}{*}{$\begin{array}{l}\text { Likelihood } \\
\text { Male }\end{array}$} & \multicolumn{2}{|c|}{ Favor odd } \\
\hline & & & & & & & & & Male & Female \\
\hline \multirow[t]{16}{*}{ Right } & 0 & 36 & 53 & 0.34 & 0.50 & 0.69 & 1.01 & 0.68 & 0.40 & 0.60 \\
\hline & 1 & 20 & 14 & 0.19 & 0.13 & 0.38 & 0.27 & 1.43 & 0.59 & 0.41 \\
\hline & 2 & 14 & 6 & 0.13 & 0.06 & 0.27 & 0.11 & 2.33 & 0.70 & 0.30 \\
\hline & 3 & 7 & 10 & 0.07 & 0.10 & 0.13 & 0.19 & 0.70 & 0.41 & 0.59 \\
\hline & 4 & 8 & 3 & 0.08 & 0.03 & 0.15 & 0.06 & 2.67 & 0.73 & 0.27 \\
\hline & 5 & 8 & 3 & 0.08 & 0.03 & 0.15 & 0.06 & 2.67 & 0.73 & 0.27 \\
\hline & 6 & 1 & 4 & 0.01 & 0.04 & 0.02 & 0.08 & 0.25 & 0.20 & 0.80 \\
\hline & 7 & 2 & 4 & 0.02 & 0.04 & 0.04 & 0.08 & 0.50 & 0.33 & 0.67 \\
\hline & 8 & 1 & 1 & 0.01 & 0.01 & 0.02 & 0.02 & 1.00 & 0.50 & 0.50 \\
\hline & 9 & 2 & 2 & 0.02 & 0.02 & 0.04 & 0.04 & 1.00 & 0.50 & 0.50 \\
\hline & 10 & 1 & 2 & 0.01 & 0.02 & 0.02 & 0.04 & 0.50 & 0.33 & 0.67 \\
\hline & 12 & 2 & 1 & 0.02 & 0.01 & 0.04 & 0.02 & 2.00 & 0.67 & 0.33 \\
\hline & 13 & 1 & 1 & 0.01 & 0.01 & 0.02 & 0.02 & 1.00 & 0.50 & 0.50 \\
\hline & 16 & - & 1 & 0.00 & 0.01 & 0.00 & 0.02 & 0.00 & 0.00 & 1.00 \\
\hline & 17 & 1 & - & 0.01 & 0.00 & 0.02 & 0.00 & - & 1.00 & 0.00 \\
\hline & 22 & 1 & - & 0.01 & 0.00 & 0.02 & 0.00 & - & 1.00 & 0.00 \\
\hline \multirow[t]{15}{*}{ Left } & 0 & 46 & 90 & 0.44 & 0.86 & 0.88 & 1.71 & 0.51 & 0.34 & 0.66 \\
\hline & 1 & 17 & 4 & 0.16 & 0.04 & 0.32 & 0.08 & 4.25 & 0.81 & 0.19 \\
\hline & 2 & 12 & 5 & 0.11 & 0.05 & 0.23 & 0.10 & 2.40 & 0.71 & 0.29 \\
\hline & 3 & 8 & 1 & 0.08 & 0.01 & 0.15 & 0.02 & 8.00 & 0.89 & 0.11 \\
\hline & 4 & 3 & 1 & 0.03 & 0.01 & 0.06 & 0.02 & 3.00 & 0.75 & 0.25 \\
\hline & 5 & 2 & 2 & 0.02 & 0.02 & 0.04 & 0.04 & 1.00 & 0.50 & 0.50 \\
\hline & 6 & 6 & 1 & 0.06 & 0.01 & 0.11 & 0.02 & 6.00 & 0.86 & 0.14 \\
\hline & 7 & 2 & - & 0.02 & 0.00 & 0.04 & 0.00 & - & 1.00 & 0.00 \\
\hline & 8 & 1 & - & 0.01 & 0.00 & 0.02 & 0.00 & - & 1.00 & 0.00 \\
\hline & 9 & 2 & - & 0.02 & 0.00 & 0.04 & 0.00 & - & 1.00 & 0.00 \\
\hline & 10 & 3 & - & 0.03 & 0.00 & 0.06 & 0.00 & - & 1.00 & 0.00 \\
\hline & 11 & 1 & - & 0.01 & 0.00 & 0.02 & 0.00 & - & 1.00 & 0.00 \\
\hline & 12 & - & 2 & 0.00 & 0.02 & 0.00 & 0.04 & 0.00 & 0.00 & 1.00 \\
\hline & 14 & 1 & - & 0.01 & 0.00 & 0.02 & 0.00 & - & 1.00 & 0.00 \\
\hline & 16 & 1 & - & 0.01 & 0.00 & 0.02 & 0.00 & - & 1.00 & 0.00 \\
\hline
\end{tabular}

$M D$ minutiae density, Frq frequency, $r M n t$ relative minutiae, $C_{;} C^{\prime} ; 0.5$

Bold text indicates manutiae density with likelihood ratio that favor males or gives equal chance for both sexes

Reinart 2014). The objectives of the present study were to determine the potential of fingerprint minutiae (level two features) in estimation of sex using likelihood ratio and posterior probability density among Hausa population as well as to determine which of the minutiae has more of the estimation power compared to others.

The frequency of pattern types in the present study is consistent with the overall rate of occurrences of fingerprints patterns, where loops are the predominant feature, followed by whorls, and the leastarches (Galton, 1892; Cummins and Midlo 1943; Reinart 2014). The higher median value of ridge ending and bifurcation combine with convergence observed in this study is in agreement with what was reported among Spanish population (Gutierrez-Redomero et al. 2007). Similarly, among African Americans and European Americans the same pattern was documented (Fournier and Ross 2016). In the process of personal identification, the less frequency of appearance of the epidermal features such as minutiae in the population reflects their importance in the forensic context. It was suggested that morphological characteristics will be more powerful indicators, 
if they are less frequent in the population than if they occurred more frequently (Gutie'rrez-Redomero et al., 2011).This indicates that the other minutiae such as short ridges may have more forensic potential than the other minutiae.

The significant difference observed in ridge ending, bifurcation \& convergence and ridge dot may provide clue on the population difference in the influence of minutiae. This is supported by previous studies among Spanish population (Gutierrez-Redomero et al. 2007; Gutie'rrez-Redomero et al., 2011). Similarly, it was reported that Caucasians and African Americans had the strongest potential for sex identification through minutiae ridge-length ratio differences with very high statistical significance. However, Native Americans, Asians, and Hispanics demonstrated insignificant differences between males and females (Reinart 2014). Gender was also not found to have a significant influence on minutiae (Fournier and Ross 2016). This led to suggestion that racial background can be considered in determining the significant sexual dimorphism (Reinart 2014). On this note, it seems necessary to explore other methods of sex estimation based on the minutiae frequency using likelihood ratio as employed in ridge density (Gutierrez-Redomero et al. 2013; Kapoor and Badiye 2015; Ahmed and Osman 2016; Rivalderia et al. 2016).

As it was observed in this study minutiae count appeared to reveal a useful likelihood ratio for sex determination. From this study likelihood ratio reveal more differences between males and females better than what was observed using independent sample analysis. This is supported by previous study (Reinart 2014). However, it is important to note that those minutiae that demonstrated statistically significant difference were the same minutiae that revealed clear likelihood ratio for sex inference. Another consideration is that the independent sample analyses may be influenced by the degree of freedom which has little or no influence on the likelihood ratio. Each ridge density is treated separately using likelihood ratio; hence the influence of outliers may not be expressed in the entire sample. In addition, it was recommended that descriptive statistics based on racial determination within the field of dermatoglyphic and larger forensic sciences community should be avoided. Likelihood ratios are calculated using probabilities based on race with regards to DNA analysis (Budowle et al. 1999; Reinart 2014).

Conversely, out of the large number of minutiae classification reported in the literature (Gutierrez et al., 2008; Gutierrez-Redomero et al., 2011; Adamu et al. 2017), only five types of minutiae were utilized in this study. This is to allow the possible application of the results in forensic cases. The five minutiae were suggested to exhibit higher degree of relevance (Fournier and Ross
2016) and the most commonly used features in the forensic investigation. The nature and variability of configurations of epidermal ridge minutiae is of direct value to forensic science in the processes of the evaluation and comparison of fingerprints of a suspect, especially of partial fingerprints left at the criminal scene (Stoney and Thornton 1986). However, the density of the minutiae varies in accordance with their location on the fingerprint (Kingston 1964; Lin 1981; Sclove 1979) and a greater density of minutiae in the nucleus and in the delta than in the periphery of the impression (Champod and Margot 1996; Gutierrez-Redomero et al. 2007).The association between the number of minutiae and the principal pattern type was also reported (Okajima 1970; Dankmeijer et al. 1980; Gutierrez-Redomero et al. 2007).

Higher sample size may reveal more information on the application of the likelihood ratio in sex inference from minutiae density. Exploring the potential of fingerprints minutiae density from other digits may be useful in providing further information that may be needed by forensic community.

\section{Conclusions}

The present study revealed the application of likelihood ratio for a possible sex inference especially in cases where knowing the sex is considered to be one of the information needed to identify a suspecting forensic case. Where no sexual dimorphism was documented for an encountered minutiae feature in the forensic scene, likelihood ratio can be useful in sex inference from those features. Increase in given type of minutiae density is likely to infer males more than females. Ridge ending minutiae was observed to have higher discriminating power as shown by higher likelihood ratio for sex inference from minutiae density among Hausa population. The likelihood ratio reveals more potential in sex inference more than can be obtained using analyses of variance statistical methods.

\section{Acknowledgements}

We thank all the participants who gave their consent to participate in this study. We also appreciated the contribution of Mr. SunusiAminu for developing fingerprint capturing and analyses software used in used in this study.

\section{Funding}

Not applicable/Nil

\section{Availability of data and materials}

Data sets generated from this study can be found at department of Anatomy, Faculty of Basic Medical Sciences, College of Health Sciences, Bayero University or on request to the following email addresses; alhassan.ana@buk.edu.ng / mgtaura.ana@buk.edu.ng

Authors' contributions

LHA \& MGT: concepts, design, definition of intellectual content, manuscript preparation, editing and review. LHA: literature search, data acquisition and analyses. Both authors read and approved the final manuscript. 


\section{Ethics approval and consent to participate}

Ethical approval was obtained from the ethical committee of Kano state Hospitals Management Board and Ahmadu Bello University, Teaching Hospital, Zaria, Faculty of Medicine (ABUTHZ/HREC/506/2015). Informed consent was obtained from all participants before their enrolment in the study.

\section{Consent for publication}

Not applicable

\section{Competing interests}

The authors declare that they have no competing interests.

\section{Publisher's Note}

Springer Nature remains neutral with regard to jurisdictional claims in published maps and institutional affiliations.

\section{Author details}

${ }^{1}$ Department of Anatomy, Faculty of Basic Medical Sciences, College of Health Sciences, Bayero University Kano, Kano, Nigeria. ${ }^{2}$ Department of Anatomy, College of Medicine University of Bisha Kingdom of Saudi Arabia, Bisha, Saudi Arabia.

Received: 29 August 2017 Accepted: 21 November 2017 Published online: 11 December 2017

\section{References}

Adamu LH, Ojo SA, Danborno B, Adebisi SS, Taura MG (2016) Sex discrimination using ridge density and thickness among Hausa ethnic groups of Kano state, Nigeria. Aust J Forensic Sci. 1-18. https://doi.org/10.1080/00450618.2016.1264477

Adamu LH, Ojo SA, Danborno B, Adebisi SS, Taura MG (2017) Sex variation in thumbprint minutiae among Hausa lineage. J Anat Sci 8(1):39-47

Ahmed AA, Osman S (2016) Topological variability and sex differences in fingerprint ridge density in asample of the Sudanese population. J Forensic Legal Med 42:25-32

Arrieta I, Martinez B, Criado B, Télez M, Ortega B, Peñagarikano O, Lostao CM (2003) Dermatoglyphic variation in SpanishBasque populations. Hum Biol 75:265-291

Ashbaugh D (1992) Defined pattern, overall pattern, and uniquepattern. J Forensic Ident 42:503-512

Babler WJ (1978) Prenatal selection and dermatoglyphic patterns. Am J Phys Anthropol 48:21-28

Barau AS (2007) The great attractions of Kano. Kano: research and documentation publications. Research and documentation directorate, government house, Kano, ISBN 978-8109-33-0

Bennett D, Perumal SA (2011) Fingerprint matching using hierarchicallevel features. Int J Comp Sci Issues 8:284-288

Borecki IB, Malhotra KC, Mathew S, Vijayakumar M, Poosha R, Rao DC (1985) Family study of dermatoglyphic traits inIndia: resolution of genetic and uterine environmental effectsfor palmar pattern ridge counts. Am J Phys Anthropol 68:417-424

Budowle B, Moretti T, Baumstark A, Defenbaugh D, Keys K (1999) Populationdata on the thirteen CODIS core short tandem repeat loci in AfricanAmericans, $U$. S. Caucasians, Hispanics, Bahamians, Jamacians, and Trinidadians. J Forensic Sci 44(6):1277-1286

Champod C, Margot PA (1996) Analysis of minutiae occurrences on fingerprints-the search for non-combined minutiae. In: Proceedings of Int assoc forensic Sci (IAFS), Tokyo, Japan

Cummins H (1967) Fingerprints: normal and abnormal patterns. Finger Print Ident Mag 49:3-31

Cummins H, Midlo C (1943) Finger prints, palms, and soles. Blackiston Co, Philadelphia

Dankmeijer J, Waltman JM, De Wilde AG (1980) Biological foundations for forensic identifications based on fingerprints. Acta Morphol Neerlando Scandinavia 18:67-83

Dorjee B, Das S, Mondal N, Sen J (2015) Dermatoglyphic variation among the Limbooof Sikkim, India. HOMO J Comp Hum Biol 66:455-470

Fournier NA, Ross AH (2016) Sex, ancestral, and pattern type variationof fingerprint minutiae: a forensic perspectiveon anthropological dermatoglyphics. Am J Phys Anthropol 160:625-632

Galton F (1892) Fingerprints. Mac Millan, London
Grieve MC, Dunlop J (1992) A practical aspect of the Bayesian interpretation of fibre evidence. J Forensic Sci Soc 32:169-175

Gutierrez-Redomero E, Galera V, Martınez JM, Alonso C (2007) Biological variability of the minutiaein the fingerprints of a sample of the Spanishpopulation. Forensic Sci Int 172:98-105

Gutierrez-Redomero E, Alonso C, Romero E, Galera V (2008) Variability of fingerprint ridge density in a sample of Spanish Caucasians and its application to sex determination. Forensic Sci Int 180:17-22.

Gutierrez-Redomero E, Alonso-Rodrıguez C, Hernandez-Hurtado LE, RodrıguezVillalba $J L$ (2011). Distribution of the minutiae in the fingerprints of a sample of the Spanish population. Forensic Sci Int 208:79-90.

Gutierrez-Redomero E, Sanchez-Andres A, Rivalderia N, Alonso-Rodriguez C, Dipierri JE, Martin LM (2013) A comparative study of topological and sex differences in fingerprint ridge density inArgentinian and Spanish population samples. J Forensic Legal Med 20:419-429

Hale AR (1952) Morphogenesis of volar skin in the human fetus. Am J Anat 91:147-181

Holt S (1952) Genetics of dermal ridges: inheritance of total finger ridge count. Ann Eugenics 17:140-161

Holt S (1968) The genetics of dermal ridges. Charles C. Thomas, Springfield, IL

Hong Y, Wan A, Jain AK (1998) Fingerprint image enhancement: algorithms and performance evaluation. IEEE Trans Pattern Anal and Mach Intell 20:777-789

Jain AK, Chen Y, Demirkus M (2007) Pores and ridges: high-resolution fingerprint matching using level3 features. Transac Pattern Anal Mach Intell 29(1):15-27

Kapoor N, Badiye A (2015) Sex differences in thumbprint ridge density in a central Indian populationEgyptian. J Forensic Sci 5(1):23-29

Kingston CR (1964) Probabilistic analysis of partial fingerprint patterns, D.Crim. Dissertation. University of California, Berkeley

Langenburg GM (2004) Pilot study: a statistical analysis of the ACE-V methodology —analysis stage. J Forensic Ident 54:64-79

Lin CH (1981) The similarity of fingerprints and the development of a singlefingerprint filing and searching system, Master's science [PhA thesis]. University of Illinois, Chicago

Mulvihill JJ, Smith DW (1969) The genesis of dermatoglyphics. J Pediat 75:579-589

National Academy of Sciences (2009) Strengthening forensic science in the United States: a path forward. The National Academies Press, Washington, D.C.

Nickell J, Fischer JF (1999) Crime science methods of forensic detection. University Press of Kentucky, Lexington, Kentucky

Okajima M (1970) Frequency of forks in epidermalridge minutiae in the fingerprint Am J Phys Anthropol 32:41-48

Reed T, Viken RJ, Rinehart SA (2006) High heritability of fingertip arch patterns intwin-pairs. Am J Med Genet 140(3):263-271

Reinart LF (2014) Investigating sex differences infingerprint minutiae density of thecore region utilizing the minutiae:ridge-length ratio. Thesis; Master of Science, Boston University. http://hdl.handle.net/2144/15325

Rivalderia N, Sanchez-Andres A, Alonso-Rodriguez C, Dipierri JE, Gutierrez Redomero E (2016) Fingerprintridge density in the Argentinean population and its application to sex inference: a comparative study. HOMO J Comp Hum Biol 67:65-84

Schaumann B, Alter M (1976) Dermatoglyphics in medical disorders. Springer Verlag, New York, pp 187-189

Scheil HG, Schmidt HD, Baltova S, Djordjevic D, Vulpe C, Siváková D, Efremovska L (2005) Dermatoglyphic studies in eastern and South-Eastern Europe. Anthropol Anz 63:393-399

Scientific Working Group on Friction Ridge Analysis, Study, and Technology. Friction ridge examination methodology for latent print examiners. Ver.1.01. 2002

Sclove SL (1979) The occurrence of fingerprint characteristics as a two dimensional process. J Am Stat Assoc 74(1979):588-595

Stoney DA, Thornton JI (1986) A method for the description of minutia pairs in epidermal ridge patterns. J Forensic Sci 31(4):1217-1234

Working draft of CDEFFS: The ANSI/NIST committee to define an extendedfingerprintfeatureset, 2008. Available at http://fingerprint.nist. gov/standard/cdeffs/index.htmli 